\title{
Well-being and acceptance - contradictory aims in forest management?
}

\section{Dörte Martens}

Keywords: urban forest, management, well-being, attitude, wilderness

\section{Abstract}

Urban forests fulfil various functions, among them the restoration process and aesthetical needs of urban residents. This article reflects the attitudes towards different managed forests on the one hand and their influence on psychological well-being on the other. Results of empirical approaches from both fields show some inconsistency, suggesting that people have a more positive attitude towards wild forest areas, while the effect on well-being is more positive after a walk in tended forest areas. A discussion follows on the link between perception and the effect of urban forests. An outlook on necessary research reveals the need for longitudinal research. The article concludes by showing management implications.

\section{Introduction}

Forests in Switzerland play an important role for identification processes for urban and rural residents alike. Management strategies for forests need to be carefully thought out and must not only serve economic and conservation intentions but also the needs of the public.

The management of protected areas is strongly influenced by different and often conflicting expectations, varying from increasing conservation efforts to increasing attention for cultural landscape preservation and immediate economic gains (Wallner \& Wiesmann 2009), which are difficult to implement in a single management strategy.

Forests fulfil different functions involving different user groups with the potential for conflicting management strategies. These forest functions include 1) serving as a carbon dioxide sink, 2) soil characteristics given by root growth, 3) providing biodiversity and habitats, 4) providing restoration and aiming at general acceptance by the public and 5) adapting the townscape to cities and urban structures (Burkhardt et al. 2008). Protected areas serve the first four functions in particular, and addressing these carefully in the management concepts can improve their quality.

Since the inclusion of psychological and social aspects is needed in a hitherto rather fact-based wilderness debate (Hunziker 1997), this article focuses on the fourth function, addressing acceptance and wellbeing in particular. Protected area management should take into account the need for both public acceptance and for a positive well-being effect. The resolution of conflicting perspectives needs a clear understanding of psychological and social factors of users.

\section{The public acceptance of wild forests}

Wilderness as a specific form of natural area with a stronger influence of natural processes than the human influence serves multiple aims, including aesthetical perception and the need for loneliness (Kaplan \& Frey Talbot 1983). Especially for urban residents, wil-
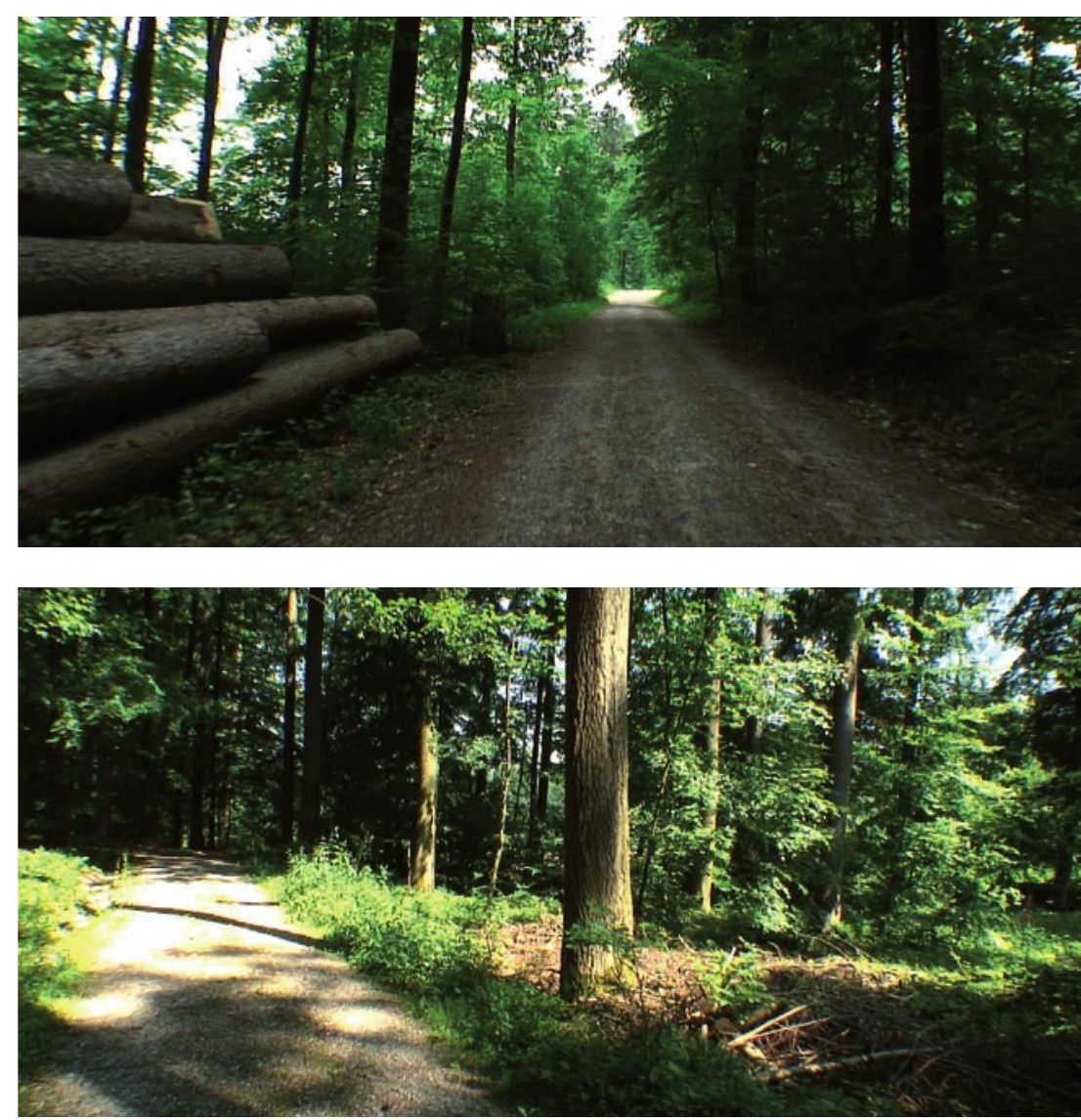

Typical tended (above) and wild (below) forests in the experiment of Martens et al. 2011. (C) Dörte Martens

derness is a positively connoted condition (Hunziker 1997). This might be due to the loss of wilderness in the cities causing the longing for untouched nature. On the other hand, historically, wilderness is mainly associated with danger and the need to be tamed and controlled. This traditional perspective is still present in rural residents who have a more positive attitude towards tamed nature: they prefer tended nature to wilderness areas, while people living in urban contexts prefer wilderness areas (Bauer 2005a; Hunziker 2000).

Thus, classifications of user groups (e.g. Bauer 2005a; Ernwein \& Höchtl 2006) help to explain dif- 
ferent user needs and behaviour. However, they do not suffice when looking for management strategies for the general public. A more generalized perspective that integrates general acceptance is needed for managing forests accessible to a large audience. An important point to consider is that highly accepted areas will be visited more often and thus provide the opportunity for well-being. The aspects of restoration and well-being will be treated in the next section, unfolding the recreational influence of natural areas from a more general perspective.

\section{The influence on well-being}

Besides aesthetical reasons, wilderness serves stress reduction by providing an escape from urban pressures (Driver 1972). This is basically due to the characteristics defined in Attention Restoration Theory (Kaplan \& Kaplan 1989). Being away is the distance from daily routines and tasks. Extent describes the perceived experience of a coherently ordered environment. Fascination is given by stimuli that attract interest, thus forcing involuntary, effortless attention. Fascination has been found to be the most important factor of restoration (Kaplan 1995; Laumann et al. 2001). Compatibility needs to be given between the environmental patterns and the person's needs and required actions. These characteristics have been shown empirically in several studies.

Various studies have shown cognitive and affective restoration to be stronger in forest environments than in urban environments (for an overview see Abraham et al. 2009). However, these results do not serve the development of management strategies of natural areas, because few studies focus on differences between different natural environments.

A recent study using an experimental field design to compare the effect of tended and wild forests presents a clearer picture (Martens et al. 2011). Since there are no wild forests in urban recreational areas in central Europe (Hunziker 1997), the study focuses on a forest which had been taken out of use six years earlier. The operationalization of the two different management strategies is shown in Table 1.

A randomized sample of urban residents of Zurich walked on a given route for 30 minutes in either the wild or the tended forest area and reported well-being in a standardized questionnaire before and after the individual walk in the forest. Results show an increase of positive well-being scales and a decrease of negative well-being scales in both conditions (see Figure 1).

Table 1 - Condensed visual differentiation of the forest conditions wild and tended in the study by Martens et al. (2011).

\begin{tabular}{|l|l|l|l|}
\hline & $\begin{array}{l}\text { Signs of economi- } \\
\text { cal use and care }\end{array}$ & $\begin{array}{l}\text { Amount of } \\
\text { dead wood }\end{array}$ & $\begin{array}{l}\text { Vegetation } \\
\text { density }\end{array}$ \\
\hline Wild forest & None & High & High \\
\hline Tended forest & $\begin{array}{l}\text { Piled cut logs near } \\
\text { path }\end{array}$ & Low & Low \\
\hline
\end{tabular}

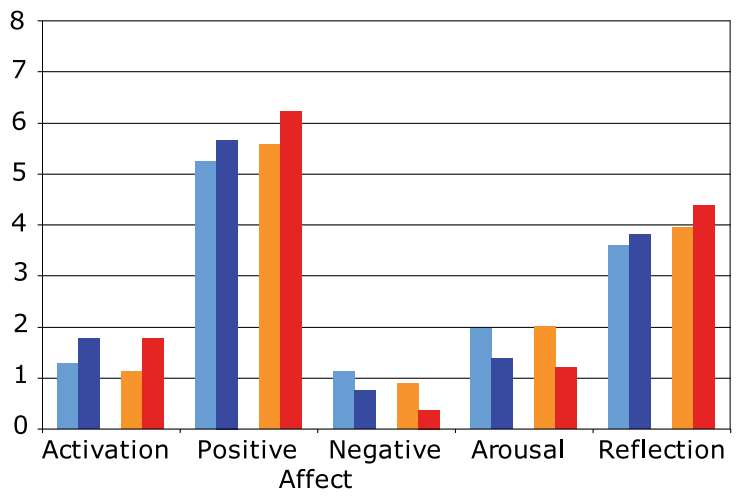

Figure 1 - Mean values of well-being pre and post measures, grouped by treatment. wild forest pre; wild forest post; tended forest pre; tended forest post. Note: Well-being scores range from 0 (not at all) to 8 (very much). $N=96$; study by Martens et al. (2011).

However, the strength of this effect depends on the management condition. Comparing the wild and tended forest condition, results show a stronger increase in positive effect and a stronger decrease in negative effect in the tended condition, while activation and arousal remain similar. This result indicates a more positive influence of tended forests compared to wild forests.

\section{Integrating results from public acceptance and well-being effects}

At first sight, this result militates in favour of intensifying the maintenance of urban forests. However, in combination with attitude studies on wilderness, the situation becomes more complex. The reported studies show more positive attitudes towards wilderness areas in urban residents (Bauer 2005b), indicating that wild forests are better accepted and would be more likely to be visited. Only forests that are actually visited can affect visitors' restoration and well-being. This is an argument for wild urban forests, even if the wellbeing effect is expected to be less strong than that of a tended forest. These conflicting perspectives show that management processes, e.g. in protected areas, need to consider both attitudes and well-being effects carefully. While wilderness provides the gratification of the need for freedom and individual exploration (Patterson \& Watson 1998), tended forests provide a calming effect by not demanding focused attention (Bauer \& Martens 2010).

An important factor discussed seems to be the amount of dead wood, which could serve as an indicator for wilderness (Hunziker 1997). If visitors are not informed about the biological function of dead wood, it arises emotional conditions characterized by sadness (Hunziker 1997). This means that detailed information for visitors is needed to optimize the less positive effect of wild forests. Information panels could explain biodiversity emerging from dead wood. However, well-being is not the only effect provided by 
wilderness areas. The main motivation for wilderness excursions is often the aesthetic perception (see Bauer 2005b), which serves a positive influence regardless of the change of well-being. As Kaplan and Frey Talbot (1983, p. 184) put it: Apparently, reactions to the wilderness experience include an increased ability to distinguish the significant from the trivial. This is in line with conservation strategies of natural areas allowing uncontrolled development of nature and wilderness.

If both the aesthetical aim of promoting acceptance and the calming effect of increased well-being shall be focused on protected forest areas, a management strategy introducing a zoning principle could be applied. As in national parks, even an urban forest could provide a core zone with protected wilderness areas and increasingly managed areas towards the outer parts. This would fulfill urban visitors' aesthetical needs for wilderness as well as providing the mood-enhancing effect of well-being in tended areas.

The temporal perspective also needs to be considered. In the short run, wilderness can even trigger situational stress such as insecurity and self-consciousness in an unfamiliar situation, as became appearent in the diaries of people taking part in a wilderness study ( $\mathrm{Ka}$ plan \& Frey Talbot 1983). This changes after some time when people have got used to the situation and turns into happiness and self-confidence about being able to control the situation. Long-term studies are desperately needed to analyse the longitudinal effect of a wilderness nature.

\section{Conclusion}

In the management of forests, both well-being and attitudes should be considered and could provide conflicting indications. These need to be carefully analysed on a long-term basis to integrate them into a concept providing recreation and general acceptance by the public. This is only one of the forest functions listed earlier (Burkhardt et al. 2008) and a coordination with other functions, such as climate, soil and biodiversity in protected areas in an interdisciplinary framework needs to be initiated.

\section{References}

Abraham, A., K. Sommerhalder \& T. Abel 2009. Landscape and well-being: a scoping study on the health promoting impact of outdoor environments. International Journal of Public Health 55 (1): 59-69.

Bauer, N. 2005a. Attitudes towards Wilderness and Public Demands on Wilderness Areas. In: S.K.I. Kowarik (ed.), Wild Urban Woodlands: New Perspectives for Urban Forstry: 47-66. Berlin.

Bauer, N. 2005b. Für und wider Wildnis soziale Dimensionen einer aktuellen gesellschaftlichen Debatte. Bern.

Bauer, N. \& D. Martens 2010. Die Bedeutung der Landschaft für die menschliche Gesundheit - Ergebnisse neuster Un- tersuchungen der WSL. Paper presented at the Forum für Wissen 2010. Landschaftsqualität. Konzepte, Indikatoren und Datengrundlagen.

Burkhardt, I., R. Dietrich, H. Hoffmann, J. Leschner, K. Lohmann, F. Schoder \& A. Schultz 2008. Urbane Wälder. Naturschutz, und Biologische Vielfalt 63.

Driver, B.L. 1972. Potential contributions of psychology to recreation resource management. In: J.F. Wohlwill \& D.H. Carson (eds.), Environment and the social sciences: 233-244. Washington, DC.

Ernwein, V. \& F. Höchtl 2006. Wenn 'Wildnis’ wahr wird. Naturschutz und Landschaftsplanung 38 (1): 13-19.

Hunziker, M. 1997. Totholz in den Nationalparkwäldern: Störfaktor oder Attraktion? Ergebnisse einer sozialwissenschaftlichen Studie. Nationalparkzeitschrift Cratschla 2: 2-9.

Hunziker, M. 2000. Einstellung der Bevölkerung zu möglichen Landschaftsentwicklungen in den Alpen. Birmensdorf: Eidgenössische Forschungsanstalt WSL.

Kaplan, R. \& S. Kaplan 1989. The Experience of $\mathrm{Na}$ ture. A Psychological Perspective. New York.

Kaplan, S. 1995. The restorative benefits of nature: Toward an integrative framework. Journal of Environmental Psychology 15 (3): 169-182.

Kaplan, S. \& J. Frey Talbot 1983. Psychological Benefits of a Wilderness Experience. In: Altman, I. \& J.F. Wohlwill (eds.), Behavior and the Natural Environment. 163-203. New York.

Laumann, K., T. Gärling \& K.M. Stormark 2001. Rating Scale Measures of Restorative Components of Environments. Journal of Environmental Psychology 21 (1): 31-44.

Martens, D., H. Gutscher \& N. Bauer 2011. Walking in 'wild' and 'tended' urban forests: the impact on psychological well-being. Journal of Environmental Psychology 31: 36-44.

Patterson, W.E. \& A.E. Watson 1998. A hermeneutic approach to studying the nature of wilderness experiences. Journal of Leisure Research 30: 423-452.

Wallner, A. \& U. Wiesmann 2009. Critical Issues in Managing Protected Areas by Multi-Stakeholder Participation - Analysis of a Process in the Swiss Alps. eco.mont 1 (1): 45-50.

\section{Author}

\section{Dörte Martens}

is a psychologist and researched the effect of natural environments on health and well-being at the Swiss Federal Research Institute WSL. In her current position as a senior researcher at the University of Potsdam, she focuses on community gardening and stress reduction in urban contexts. 